\title{
8th Interventional MRI Symposium
}

\section{September 24-25, 2010, Leipzig, Germany}

(C) Springer Science+Business Media, LLC and the Cardiovascular and Interventional Radiological Society of Europe (CIRSE) 2009

This symposium is focused on the field of interventional MRI. Presentations and poster sessions will be held on both basic experimental studies and clinical applications. The symposium will provide a forum where scientists and clinicians can contribute their knowledge and experience in this special field.

Scientific Program Committee: Thomas Kahn (Leipzig, Germany), Jonathan S. Lewin (Baltimore, USA), Ferenc A. Jolesz (Boston, USA).

Scientific topics will include: Interventional MRI Systems, Instrumentation, Anesthesia and Monitoring, Specialized MR Imaging Techniques, Visualization Techniques and Data Processing, MR Thermometry, Drug Delivery, Therapy Planning, Safety Aspects, Economic Issues, and much more.

For further information, contact: Prof. Thomas Kahn, University of Leipzig. Telephone: 493419717 400; Fax: 493419717 409; email: interventional.mri@medizin.unileipzig.de.

Note: To add a listing to the journal's Announcements page, please email your information to Deana Rodriguez at rodriguezcvir@gmail.com. All announcement submissions are subject to the Editors' approval. The deadline for each issue is 2 months prior to publication. 